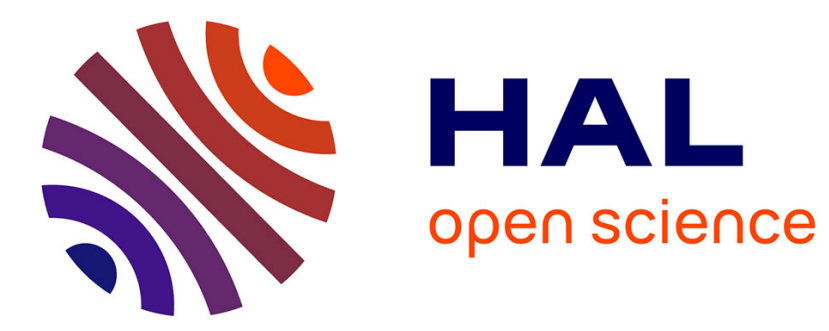

\title{
Amazonian Deforestation, Environmental Kuznets Curve and Deforestation Policy: A Cointegration Approach
}

Philippe Polomé, Jérôme Trotignon

\section{- To cite this version:}

Philippe Polomé, Jérôme Trotignon. Amazonian Deforestation, Environmental Kuznets Curve and Deforestation Policy: A Cointegration Approach. 2016. halshs-01274854

\section{HAL Id: halshs-01274854 \\ https://shs.hal.science/halshs-01274854}

Preprint submitted on 16 Feb 2016

HAL is a multi-disciplinary open access archive for the deposit and dissemination of scientific research documents, whether they are published or not. The documents may come from teaching and research institutions in France or abroad, or from public or private research centers.
L'archive ouverte pluridisciplinaire HAL, est destinée au dépôt et à la diffusion de documents scientifiques de niveau recherche, publiés ou non, émanant des établissements d'enseignement et de recherche français ou étrangers, des laboratoires publics ou privés. 


\title{
GATE

UMR 5824

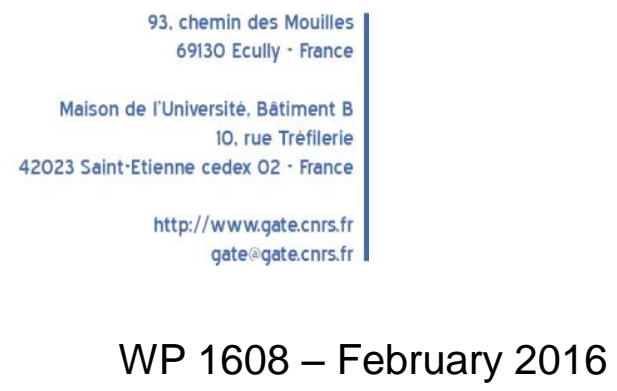

\section{Amazonian Deforestation, Environmental Kuznets Curve and Deforestation Policy: A Cointegration Approach}

\author{
Philippe Polomé, Jérôme Trotignon
}

\begin{abstract}
:
Brazilian Amazon deforestation rate is found to display a unit root and to be cointegrated with Brazilian GDP and its square - An Environmental Kuznets Curve (EKC). Although, it is not the first time that such an EKC is detected, this may be the first such time-series evidence. Detecting an EKC is hampered by several econometric issues that have been shown to lead to possibly spurious results in cross-section and panel contexts, but are satisfactorily addressed in a cointegrated (time-series) framework. Alternative theories for explaining the deforestation path are rejected. There is evidence that the "Action Plan" of the Brazilian government against deforestation had an important effect. These results are in contrast to the economics literature on an EKC in emissions such asCO2, but appear to be consistent with a geographical sciences literature that considers that deforestation declines when alternative activities become available.
\end{abstract}

Keywords:

Amazon deforestation; unit root; cointegration; "Action Plan" policy; Environmental Kuznets Curve

JEL codes:

C22, Q23, Q28

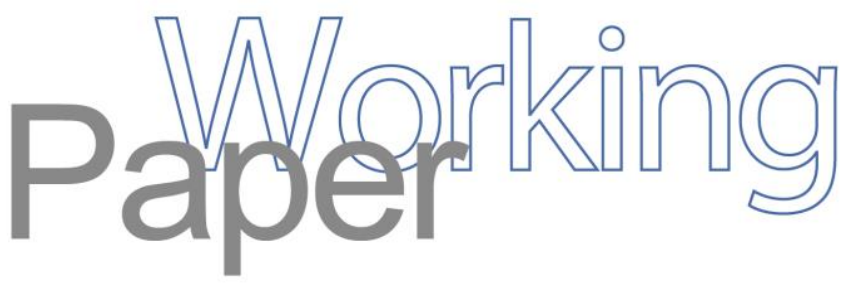




\title{
Amazonian Deforestation, Environmental Kuznets Curve and Deforestation Policy: A Cointegration Approach
}

\author{
Philippe Polomé and Jérôme Trotignon
}

Feb. 2016

Université de Lyon, Lyon, F-69007, France ; CNRS, GATE Lyon Saint-Etienne, Ecully, F-69130, France.

\begin{abstract}
Brazilian Amazon deforestation rate is found to display a unit root and to be cointegrated with Brazilian GDP and its square - An Environmental Kuznets Curve (EKC). Although, it is not the first time that such an EKC is detected, this may be the first such time-series evidence. Detecting an EKC is hampered by several econometric issues that have been shown to lead to possibly spurious results in cross-section and panel contexts, but are satisfactorily addressed in a cointegrated (time-series) framework. Alternative theories for explaining the deforestation path are rejected. There is evidence that the "Action Plan" of the Brazilian government against deforestation had an important effect.

These results are in contrast to the economics literature on an $\mathrm{EKC}$ in emissions such as $\mathrm{CO}_{2}$, but appear to be consistent with a geographical sciences literature that considers that deforestation declines when alternative activities become available.
\end{abstract}

JEL. C22 Time-Series Models, Q23 Forestry, Q28 Government Policy

Keywords. Amazon deforestation; unit root; cointegration; "Action Plan” policy; Environmental Kuznets Curve 


\section{Introduction}

This paper is about understanding the path of deforestation of the Amazon Rainforest in a time-series context, with a particular interest in the last decade that has witnessed a steep decline in deforestation rate. There are many reasons why deforestation in the Amazon region is an important issue. The erosion of the biodiversity reservoir due to habitat loss is a well-known one. $\mathrm{CO}_{2}$ emissions consitute another one as the Amazon rainforest is an important carbon sinkhole, but also because deforestation emits carbon, first because deforesting is accompanied (or even effected) by burning the vegetation, but also because a newly deforested soil releases carbon. ${ }^{1}$ These are the famous LULUCF emissions (Land use, land-use change and forestry); they account for about $60 \%$ of total Brazilian emissions using the 2006 IPCC GreenHouse Gas accounting protocol [11]; ${ }^{2}$ in the "Legal Amazon" region, the focus of the present paper, ${ }^{3}$ these are primarily deforestation. Deforestation also causes changes of moisture in the air, which are widely recognized to cause droughts down South. The Amazon forest soil nutrients are mainly in the tree cover; once deforested, these nutrients form a thin layer over a relatively depleted soil, that layer is quickly (a few years) washed away by the the rains, causing soil erosion and flash floods; the soil is then poorly suited for most crop cultivation but supports relatively well planted pasture (Margulie et.al. 2004 [22]).

The causes of deforestation are certainly complex, but are primarily driven by human action, thus deforestation may compete with other economic activities. Following the World Bank 2004 report [22], these causes have changed over time. The 70's and 80 's deforestation had been induced by government policies and subsidies. In the $90 \mathrm{~s}$ and early $00 \mathrm{~s}$, it is attributed mainly to cattle ranching, and to soybean cultivation to a much lesser extent, consistently with the properties of the Amazon basin soil. As of 2004, 70\% of formerly forested land in the Amazon, and $91 \%$ of land deforested since 1970, is used for livestock pasture. Agriculture and cattle ranching may be more profitable in the Amazon due to weak land titling, land grabbing, irregular labor contracts, and the continuous process of opening up of new forest areas. The later are carried out at low cost by small farmers who "prepare" the land for medium- and large-scale cattle ranching which follow them, sometimes against their will. Currently, slash and burn agriculture appears much less prevalent than it was; small farmers are less blamed than they once were. It is important to underline that deforestation is not development and is more akin

\footnotetext{
${ }^{1}$ IPCC Special Report on Land Use, Land-Use Change And Forestry at http://www.grida.no/publications/other/ipcc_sr/.

${ }^{2}$ These figures are rapidly changing according to the 2104 report "Estimativais anuais de emissoes de gazes de efeito estufa", Ministerio da Ciença tecnologia e inovaçao, 2da Edicao, where the figure falls down to 14,6\% in 2012 compared to 57,9\% given for 2005.

${ }^{3}$ Legal Amazon "Amazônia Legal" is a Brazilian region defined by law; it includes several states and federal regions for a total of about 4.9 million sq. $\mathrm{km}$, that is about $600000 \mathrm{sq} \mathrm{km}$ bigger than the EU or about one half the USA. It includes mostly, but not only tropical rainforest.
} 
to a lawless process of land grabbing, in which the small actors, including the indigenous people, are certainly not the winners.

Roads are also sometimes evoked as a factor explaining deforestation. Weinhold and Reis (2008) [36] analyze the way roads creation induces deforestation. They show that it does only in areas that have not seen deforestation but it reduces deforestation in areas where land is already cleared. Nasa Earth Observatory ${ }^{4}$ may summarize a general opinion:

\footnotetext{
This pattern follows one of the most common deforestation trajectories in the Amazon. Legal and illegal roads penetrate a remote part of the forest, and small farmers migrate to the area. They claim land along the road and clear some of it for crops. Within a few years, heavy rains and erosion deplete the soil, and crop yields fall. Farmers then convert the degraded land to cattle pasture, and clear more forest for crops. Eventually the small land holders, having cleared much of their land, sell it or abandon it to large cattle holders, who consolidate the plots into large areas of pasture.
}

Following a literature belonging more to geographical sciences than economics, Kauppi et.al. (2006) [20] find that above a certain level of income, countries stop to deforest. Their evidence is essentially a world-wide crosssection. This points to an explanation economists are familiar with: Deforestation as worldwide cross-section follows an Environmental Kuznets Curves (EKC), suggested by Grossman \& Kruger (1991) [17] and (1995) [18] and by Shafik and Bandyopaddhay (1992) [30] for deforestation. As is well-known, the EKC hypothesis postulates that environmental damage first worsen and then recover as income per capita rises, for a variety of causes: environmental consciousness, different economic opportunities, policies... These causes can be either chronological or truly income-related. This may apply to a variety of "pollutants", including emissions and deforestation.

More formally, the EKC is an inverted U-shaped curve: to larger levels of income are associated gradually lower levels of pollutants, to the extent that actual emissions may reach a point where they become negative. The theory can be expressed in a polynomial of degree two, valid for any pollutant or environmental impact $y$ and income measure such as Gross Domestic Product per inhabitant GDPh and its square, that is

$$
y_{t}=\beta_{0}+\beta_{1} G D P h_{t}+\beta_{2} G D P h_{t}^{2}+\gamma x_{t}+\varepsilon_{t}
$$

where $x$ are further determinants that will be discussed later and $\varepsilon$ is an error term. If $\beta_{1}>0$ and $\beta_{2}<0$, the stock of the pollutant ends up diminishing, possibly faster than the natural rate of pollution absorption.

\footnotetext{
${ }^{4}$ Anonymous, 2012 data, accessed October 2015 at http://earthobservatory.nasa.gov/Features/WorldOfChange/deforestation.php
} 
Stern 2004 [32], reviewing a large literature consisting primarily of cross-section or panel studies that found an EKC on occasion for $\mathrm{CO}_{2}$ and $\mathrm{CO}_{2} e q$ emissions, proposes that the observed $\mathrm{EKC}$ is actually an artifact of the analysis. That is, the results are spurious. Instead, the apparent EKC is a mixture of effects as follows: Pollution increases roughly monotonically (linearly) with income, but "time" reduces pollution, that is, incomeindependent policies. In rapidly growing middle-income countries, the income effect (increasing pollution) overwhelms the time effect. In wealthy countries, growth is slower, and pollution reduction efforts can overcome the income effect. That is what causes an apparent EKC effect in cross-section or panel data sets.

Testing an EKC using cross-sectional country (or region) data assumes that all countries are situated on the same quadratic curve if there is indeed an EKC. Notwithstanding the spurious issue just mentioned, rejecting an EKC using cross-sectional data does not imply that an EKC is not present for any particular country. Testing an EKC using panel data makes the hypothesis that countries will essentially follow the same path (slope of GDP regressor) starting from different points (the intercepts), that is, substituting geographical data in place of the missing time series. However, the EKC hypothesis is not that all countries (or regions) follow the same trajectory, only that there is an inflection point in emissions. More formally, it seems reasonable to assume that, if the EKC hypothesis is true, each country follows its own path, that is $y_{i t}=\alpha_{i}+\beta_{i} G D P h_{i t}+\gamma_{i} G D P h_{i t}^{2}+\gamma x_{i t}+$ $\varepsilon_{i t}$. However, in a cross-section, the model is $y_{i}=\alpha+\beta G D P h_{i}+\gamma G D P h_{i}^{2}+\gamma x_{i}+\varepsilon_{i}$ and a panel-data model is $y_{i t}=\alpha_{i}+\beta G D P h_{i t}+\gamma G D P h_{i t}^{2}+\gamma x_{i t}+\varepsilon_{i t}$. That is, a cross-section forces all countries to the same path and a panel only allows a different starting point but imposes the same curvature.

Comparing deforestation across countries, Barbier and Burges (2001) [4], in a survey of the economics of tropical deforestation, indicate that even if countries might follow an EKC, they are unlikely to follow all the same path. Lambin and Meyfroidt (2011) [21], using forest cover evidence in a geographical study, indicate that "there is no default forest transition pathway". In other words, only time-series models offer sufficient flexibility (different intercept and slopes) to effectively test an EKC.

Following a well-kown (e.g. Wooldridge 2012 [37]) literature, and also as argued for the case of the EKC in Stern (2004) [32], Day and Grafton (2003) [10] and Bernard et.al. (2011) [5], the EKC econometric issues can be summarized in a nutshell as follows. A deforestation time-series may present a unit root, so that inference from regressions results could be flawed, unless a cointegration relation can be found. Since income series often also present a unit root, an EKC could be such a relation. Generally, regressing a unit root on a unit root is spurious unless these series are cointegrated, that is some linear combination of the series is not a unit root. 
Thus an EKC relation could only be conclusively shown if it is part of a cointegration relation. ${ }^{5}$ There is a large literature on these issues in econometrics, especially in finance and macroeconomics.

Reliable long forest cover time series are however quite rare and do not appear available for many well-known large forests such as Indonesia, Congo or Russia. There are detailed forest-cover for Canada but available records start in 1989 [15], well after deforestation had ceased to be an issue. The Legal Amazon rainforest is possibly the only exception since it has been regularly monitored for nearly 40 years now. Brazilian deforestation outside of the Legal Amazon is only known as averages over large time periods.

Following Choumert et al. (2013) [7] meta analysis on EKC in deforestation on nearly 70 studies, there are only 6 results using time-series for analyzing deforestation. These appear to be Shafik (1992) [30], who does not consider cointegration (or order of integration of the series), and thus cannot investigate EKC in the longterm as discussed above. Ewers et.al. (2008) [13], in a correlation analysis, use a 1990-2005 sample over the Amazon basin, but fail to acknowledge the potential for unit roots. For Latin America, an EKC was identified in 2 panel studies of deforestation, both using FAO data over similar periods from the early 70's to the early 90 's: Bhattarai and Hammig (2001) [6], and Culas and Dutta (2003) [9]. For the Legal Amazon, Araujo et al. [2] found a weakly significant Kuznets effect using panel data for the 1988-2000 period and 9 States. The samples in these last five papers end too early to detect the steep post-2004 decline in deforestation. Corrêa de Oliveira et.al. (2011) [24] focused on deforestation at the municipal level in a spatial panel (2001-2006) model. They found a cubic "inverted N-shaped" relation when accounting for spatial correlation. None of these deforestation papers appear to account for the presence of unit roots in the series.

Kauppi et.al. [20] use data collected over a wide range of countries over the world. That is a cross-section and the Stern (2004) [32] critique summarized above in the context of emissions applies : the correlation between income and deforestation could be spurious as it could be not income-dependent, but rather time-related. That is, only time-related causes would drive emissions reductions and such reductions appear in richer countries only because they have been on a longer development path.

In the literature about emissions, when time series issues of unit roots are accounted for, an apparent EKC is sometimes revealed to be spurious. For example, Perman and Stern (2003) [27] conclude that an EKC relation does not exist using a panel dataset of sulfur emissions for 74 countries over a span of 31 years; they account for (panel) unit-root and test cointegration. Day and Grafton (2003) [10] tested for unit roots and cointegration

\footnotetext{
${ }^{5}$ As reviewed in Payne et.al. (2006) [25], a similar issue arose in researching Wagner's "law" (the expansion in public sector expenditures is positively related to the level of economic development), where cointegration gradually became the dominant approach.
} 
between each of several emissions ( $\mathrm{CO}, \mathrm{CO}_{2}, \mathrm{SO}_{2}$ and fine particles) and per capita income, for relatively short annual series $(T \leq 38)$ in Canada. They found unit roots using Augmented Dickey-Fuller (ADF) and Phillips-Perron tests, but fail to find cointegration evidence using Engle-Granger and Johansen tests.

This paper proposes to test cointegration for the Legal Amazon deforestation with GDPh and its square, and estimate the vector of cointegration coefficients. Additional factors might enter this relation. Considering the small sample size, it is difficult to estimate a large cointegration relation at the outset; instead, the methodology is sequential. After testing for cointegration of the EKC relation, in a second step, other factors, e.g. Population or Meat price, are introduced and it is examined whether they alter the cointegration tests results. It is also tested whether these regressors are cointegrated with deforestation without $G D P h$ in the relation. Unit roots regressors should be excluded from the Deforestation model when they are not co-integrated, since they induce a risk of spurious correlation and when irrelevant, make the tests loose power. An I(0) ("non-unit root") regressor cannot be in a cointegration relation, but is legitimate in a regression.

One such factor that is of particular interest is the Action Plan (AP) for Prevention and Control of the Legal Amazon Deforestation (Plano para Prevenção e Controle do Desmatamento na Amazônia - PPCDAm), the Brazilian policy started in $2004^{6}$ with a budget set per phases of $4-5$ years. The AP is little correlated (13\% from 2004 to 2014) to the Brazilian GDP, thus omitting it from analysis of the EKC might not be an issue and cointegration may be studied separately from its effect. The converse, intending to assess the effect of the AP outside of a cointegration relation, might lead (and does in this case) to spurious results since deforestation presents a unit root.

The rest of the paper is organized as follows. Section 2 describes the data. Section 3 presents the EKC model, discusses its time-series properties, proceeds to estimation and compare EKC with the alternative theory suggested by Stern (2004) [32]. Section 4 considers broad unobserved heterogeneity issues, test the inclusion of the population, agricultural prices and Action Plan policy series, and discusses additional untested potential drivers. The last section concludes and discusses expected deforestation paths.

\footnotetext{
${ }^{6}$ Brazilian Ministry for the Environment - Ministério do Meio Ambiente http://www.mma.gov.br/florestas/controle-epreven\%C3\%A7\%C3\%A3o-do-desmatamento/plano-de-a\%C3\%A7\%C3\%A3o-para-amaz\%C3\%B4nia-ppcdam
} 


\section{Data}

Data on deforested area are available from the PRODES project of the Instituto de Pesquisas Espaciais since 1975 [26], but are not available every year until 1988. ${ }^{7}$ Between 1975 and 1988, deforested area of the Legal Amazon appears to have been monitored by Landsat every two or three years. Following Andersen et al. (2002) [1], this is a gross measure since once deforested, a plot is not re-considered in the interpretation of the satellite images, so that secondary (re-grown) forests is never counted. Therefore missing data are necessarily bounded between the deforested areas at the periods immediately preceding and following it.

Interpolation can still be computed by several means. The piecewise linear approximation of the deforested area has been selected as alternative assignation procedures (e.g. OLS using a linear or quadratic trend) lead to more unexplained variations of the deforestation rate. Figure 1 presents the time profile of deforested area and deforestation in the Legal Amazon. Deforestation is computed as the yearly change in deforested area.

Figure 1: Time Profile of Legal Amazon Deforestation

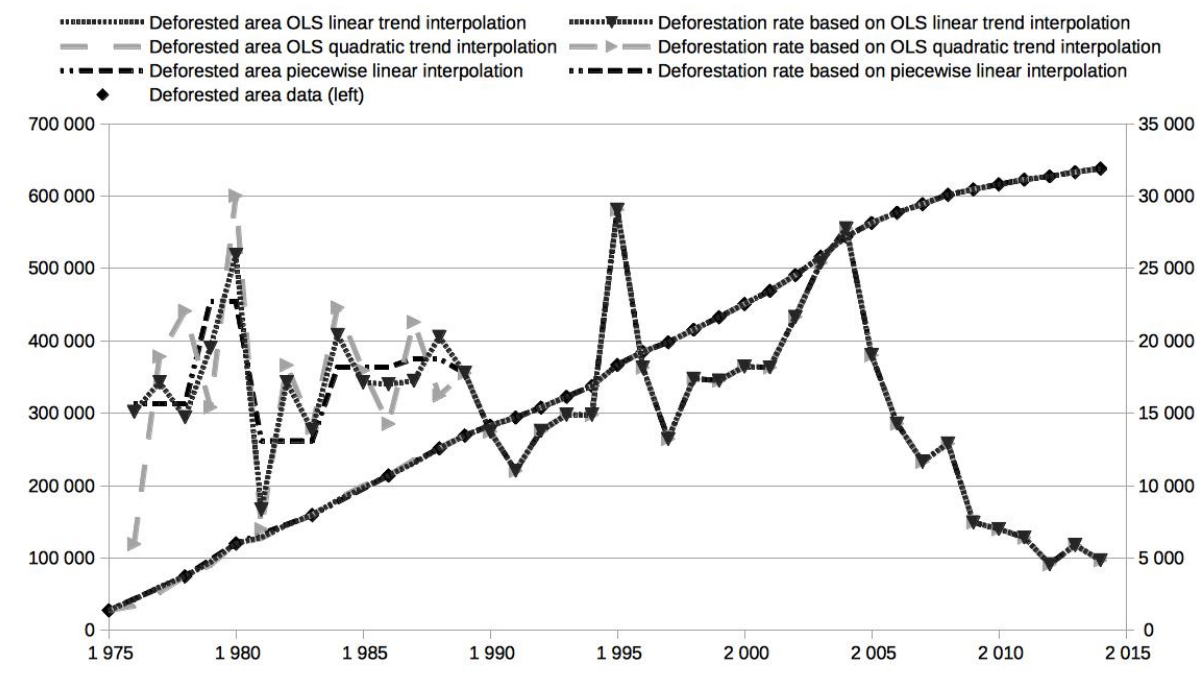

The initial 1975 deforested area appears small compared to later years, but the PRODES data match quite well independent estimates by Skole and Tucker [31] and is also consistent with Fearnside (1982) [14] early assessment. The 1995 peak was attributed to accidental forest fires [22]. The steep decline of deforestation after 2004 is the most striking feature of the series, and is the main focus of this paper. The available time-span for deforestation (1975-2014) remains relatively short, and that limits the scope of the analysis.

\footnotetext{
${ }^{7} 1989$ report available from the Coordenação-Geral de Observação da Terra at http://www.obt.inpe.br/prodes/index.php, accessed at time of writing.
} 
Some other data used in the present paper proceed from the World Bank. The income per capita, GDPh, is measured as Gross Domestic Product in constant 2005 US\$ divided by midyear population. ${ }^{8}$ Often, studies of an EKC effect in deforestation have used local income, e.g. municipal income for deforestation at the municipal level. However, Kauppi et.al. (2006) [20] emphasize the idea of economic opportunities as a driver of the decrease in deforestation. In that sense, the local income might be largely irrelevant and the national income might better reflect opportunities. It is apparent that the sharp decrease in deforestation starts to occur in 2004 when GDPh reaches about 4 650, which is also a point of growth acceleration in Brazil. ${ }^{9}$ Population is the total Brazilian population; its yearly change reflects a number potential pressures stemming neither from $G D P h$ nor from a possible time trend, but only from the bulk of the population, possibly through internal migration. The main data used for the present study are summarized in Table (1).

Table 1: Main Statistics, time span 1975-2014

\begin{tabular}{|c|c|c|c|c|c|c|}
\hline Variables & Content & Mean & s.e. & NA & Unit & Source \\
\hline$G D P h$ & GDP per capita & 4443 & 709 & 0 & Constant US\$2005 & \multirow{2}{*}{ World Bank } \\
\hline Pop & Population & 159 & 28.8 & 0 & $10^{6}$ inhabitants & \\
\hline Area & Deforested area & \multicolumn{2}{|c|}{637891 in 2014} & $0^{\#}$ & $\mathrm{~km}^{2}$ & \multirow{2}{*}{ INPE - PRODES } \\
\hline Defor & Deforestation rate & 15646 & 5801 & 0 & $\mathrm{~km}^{2} /$ year & \\
\hline$A$ & Action Plan Policy & 413 & 101 & 0 & Constant US\$2005* & Official $^{\dagger}$ \\
\hline
\end{tabular}

\# Values for years 1976, 1977, 1979, 1981, 1982, 1984, 1985 and 1987 were linearly interpolated.

* Budget starts in 2004, mean and s.e. are calculated starting in 2004.

$\dagger$ Brazilian Ministry for the Environment - Ministério do Meio Ambiente: http://www.mma.gov.br/florestas/controle-epreven\%C3\%A7\%C3\%A3o-do-desmatamento/plano-de-a\%C3\%A7\%C3\%A3o-para-amaz\%C3\%B4nia-ppcdam

\section{Environmental Kuznets Curves and Cointegration}

The primary interest of the present paper is to assess whether deforestation is linked to income in the Kuznets (quadratic) sense. The model under consideration is the following one:

$$
\text { Defor }_{t}=\beta_{0}+\beta_{1} G D P h_{t}+\beta_{2} G D P h_{t}^{2}+\gamma x_{t}+\varepsilon_{t}
$$

Further exogenous or endogenous variables $x_{t}$ may enter the relation, and conceivably there could be a more sophisticated cointegration relation. In a first step, the focus will be on the "pure" EKC relation without additional

\footnotetext{
${ }^{8}$ World bank definition: "GDP is the sum of gross value added by all resident producers in the economy plus any product taxes and minus any subsidies not included in the value of the products. It is calculated without making deductions for depreciation of fabricated assets or for depletion and degradation of natural resources."

${ }^{9}$ It is interesting to quote Kauppi et.al. [20]: "The growing stock in a sample of 50 nations did not change regularly with GDP at low levels of GDP per capita, but with one exception, the growing stock grew from 1990 to 2005 in the nations with more than approximately $\$ 4,600$ GDP per capita." The authors did not indicate whether these were current dollars.
} 
regressors

$$
\text { Defor }_{t}=\beta_{0}+\beta_{1} G D P h_{t}+\beta_{2} G D P h_{t}^{2}+\varepsilon_{t}
$$

It is acknowledged that deforestation might be driven by many other socio-economic factors as in Araujo et al. [2]. From an econometric standpoint, it is more usual to specify a broad model and possibly exclude some regressors. In the present case for example, unit root variables should be excluded if they are not relevant, as they may lead to spurious results. However, the size of the dataset - 40 observations - makes the usual strategy unrealistic. The methodology is the following. First, each series is tested for unit roots using the classical Augmented Dickey-Fuller (ADF) and Phillips-Perron (PP) tests, then cointegration is tested using the Engle-Granger and Johansen tests. Next, on the basis of Stern (2004) [32], alternative theories are tested for cointegration. Finally, cointegration with additional variables is tested one variable at a time.

\subsection{Unit Roots}

Informally, a unit root characterizes a stochastic process $x$ for which the correlation between two points in time, $x_{t}$ and $x_{t+h}$, does not decrease as time between them, $h$, increases. A useful intuition for such a process starts from the autoregressive process of order one, $\operatorname{AR}(1), x_{t}=\rho x_{t-1}+\varepsilon_{t}, t=1,2, \ldots$ where $\varepsilon$ is a white noise. Such a process is said to be stable if $|\rho|<1$. It is easy to show that the covariance between two point in time depends only on $\rho$ and on the variance of the error term $\sigma_{\varepsilon}^{2}: \operatorname{cov}\left(x_{t}, x_{t+h}\right)=\rho^{h} \sigma_{\varepsilon}^{2} /\left(1-\rho^{2}\right)$, which converges to zero when $h \rightarrow \infty$. Stable AR(1) processes are called weakly dependent or $I(0)$. Weak dependance is critical in a regression context as the usual OLS inference procedures are only valid if all the series in the regression are $I(0) .^{10}$

When $\rho=1$, the $\operatorname{AR}(1)$ is called a random walk $x_{t}=x_{t-1}+\varepsilon_{t}$ and is said to be $I(1)$ or to have a unit root. A unit root is thus characterized by persistent behaviors, that is a shock in one period has non-diminishing effects in the future. That is not the same as trending. For example, a shock in deforestation, due to a forest fire, could have lasting effects on future deforestation as the burnt land might be used to access further land. Regressing an $I(1)$ on an $I(1)$ often leads to spurious results, that is, irrelevant regressors appear significant, possibly misleading interpretation. GDPh and population are often considered unit roots, e.g. Wooldridge (2012) [37], but there does not seem to be such a definitive opinion on deforestation.

\footnotetext{
${ }^{10}$ The series must also be stationary. A stationnary process $x$ is such that its distribution (including its parameters) does not change in time. Trends such as $x_{t}=\alpha_{0}+\alpha_{1} t+\varepsilon_{t}$, where $\varepsilon_{t}$ is a white noise, are not stationnary as their expectation increases with time; random walk $x_{t}=x_{t-1}+\varepsilon_{t}$ are not stationnary as their variance increases with time. Stationarity is the time-series equivalent of "identically distributed" in cross-section.
} 
Let $\rho_{1}=\operatorname{Corr}\left(y_{t}, y_{t-1}\right)$; the sample correlation between $y_{t}$ and $y_{t-1}$ is an estimator of $\rho_{1}$, $\hat{\rho}_{1}$. The sampling distributions of the estimator $\hat{\rho}_{1}$ are very different when $\rho_{1}$ is close to one than when it is not; in the foremr case, $\hat{\rho}_{1}$ can have a severe downward bias, so that specific tests have been developed. Table ((2)) presents $\hat{\rho}_{1}$ values for the main series of Table (1). The unit root tests are the well-known Augmented Dickey-Fuller (ADF) and Phillips-Perron (PP) tests. The ADF test is specified with a maximum of three lags because the data is annual and tested down on the basis of an Akaike Information Criterion (AIC). The selected number of lags is indicated in Table (2). To avoid loosing power, no more lag were investigated as the series is annual (Wooldridge 2012 [37]). Results are presented with a drift (constant) $\alpha$ alone and adding a trend $\beta t$, for each test.

Following the EKC relation presented earlier, only the variables in levels, not in log, are of interest. Further, even if the current measure of deforestation cannot become negative (Andersen et.al. 2002 [1]), transforming in log might change forecasts when they approach zero. First-differences naturally comes to mind with unit roots, but first-differences are short-term changes, and thus cannot reflect the long-term nature of the EKC. It is still of interest to assess whether short-term changes in $G D P h$ affect short-term changes in deforestation, but it cannot be taken as evidence for or against an EKC.

Table 2: Unit Root Tests

\begin{tabular}{|c|c|c|c|c|c|c|c|c|c|c|c|c|c|c|c|c|}
\hline & \multicolumn{2}{|c|}{ Defor. } & \multicolumn{2}{|c|}{$\Delta$ Defor. } & \multicolumn{2}{|c|}{$G D P h$} & \multicolumn{2}{|c|}{$\triangle G D P h$} & \multicolumn{2}{|c|}{ Pop. } & \multicolumn{2}{|c|}{$\triangle P$ Pop. } & \multicolumn{2}{|c|}{ Meat price } & \multicolumn{2}{|c|}{$\Delta$ Meat price } \\
\hline & p-val & Lags & $\mathrm{p}$-val & Lags & p-val & Lags & p-val & Lags & $\mathrm{p}$-val & Lags & p-val & Lags & p-val & Lags & p-val & Lags \\
\hline $\mathrm{ADF} \mathrm{w} /$ constant & .58 & 2 & 0 & 1 & .99 & 2 & .01 & $\overline{1}$ & 0 & 2 & $\overline{9.94}$ & 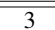 & .84 & 2 & .09 & 3 \\
\hline $\mathrm{ADF}$ w/ constant \& trend & .65 & 2 & 0 & 1 & .89 & 2 & .015 & 1 & .60 & 2 & .63 & 3 & .99 & 2 & .004 & 3 \\
\hline Phillips-Perron w/ constant & .24 & - & 0 & - & .98 & - & .0001 & - & 0 & - & .98 & - & .71 & - & 0 & - \\
\hline $\mathrm{PP}$ w/ constant \& trend & .31 & - & 0 & - & .90 & - & .0001 & - & 1 & - & .36 & - & .98 & - & 0 & - \\
\hline$\hat{\rho}_{1}$ & \multicolumn{2}{|c|}{.70} & \multicolumn{2}{|c|}{$\begin{array}{l}.09 \\
\end{array}$} & \multicolumn{2}{|c|}{.98} & \multicolumn{2}{|c|}{.13} & \multicolumn{2}{|c|}{1.00} & \multicolumn{2}{|c|}{.99} & \multicolumn{2}{|c|}{.84} & \multicolumn{2}{|c|}{-.05} \\
\hline
\end{tabular}

Augmented Dickey-Fuller (ADF) and Phillips-Perron unit root tests asymptotic p-values as implemented in the Gretl package [8]. The symbol $\Delta$ indicates first differences.

Following both the ADF and the PP tests, neither GDPh nor Deforestation appear to include a deterministic trend in the sense that the tests results do not change much when a trend is included, as is the case with the Population series. Table (2) variables present unit roots in levels beyond reasonable doubt. The same tests clearly reject unit roots for first-differences in $G D P h$ and in Deforestation, so that OLS regression results may be interpreted in the usual sense. Table (5), below, shows that a quadratic relation also holds in first-differences between Deforestation and $G D P h$, but since there is no underlying theory for such relation, interpretation is purely in terms of correlation. 


\subsection{Cointegration}

Cointegration means that although two series are $I(1)$, some linear combination of them is $I(0)$, making regression of one on the other meaningful, instead of spurious. The behavior of these variables can then be analyzed in levels in a long term sense. Analyzing cointegration of the series in Table ((2)) is then interpreted as testing whether they obey an equilibrium relationship in the long-run, even though they may diverge substantially from that equilibrium in the short run. Because the series of interest are unit roots, it is essential that they be cointegrated, otherwise the significance of the regressors cannot be known.

The cointegration tests that have been used are the Johansen Lmax and Trace tests, adjusted for small sample, and the Engle-Granger test. These tests have versions depending on whether a deterministic time trend and/or a constant is included in the cointegration relation [1]. It is not immediate to distinguish a variable that include a deterministic trend from a unit root; the latter are sometimes called "stochastic trend" variables because, graphically, they may appear to have an upward or a downward trend for a long time before returning to their expected values. No deterministic trend has been included in the cointegration tests as the unit root tests indicated that Deforestation was not trending, while it was undoubtedly $I(1)$. It is also arguable whether there should be a constant in the cointegration relation, but there is no imperious reason to exclude it.

The Engle-Granger test starts with three lags and proceed downward to maximize the AIC ${ }^{11}$, typically halting at one lag with the present data. The test must present a small p-value to reject a unit root in the residuals of the cointegration regression. Table (3) presents the results of the Engle-Granger test.

Table 3: Engle-Granger Cointegration Tests Results

\begin{tabular}{|c|c|c|c|c|c|c|}
\hline Engle-Granger & \multicolumn{2}{|c|}{ Without trend } & \multicolumn{2}{c|}{ With linear trend } & \multicolumn{2}{c|}{ Quadratic trend } \\
\hline Coint. regression & Coef. estimate & $\mathrm{p}$-value & Coef. estimate & $\mathrm{p}$-value & Coef. estimate & $\mathrm{p}$-value \\
\hline \hline Intercept & -115973 & .001 & -145942 & .003 & -160160 & .002 \\
\hline$G D P h$ & 60.36 & $<.001$ & 72.47 & .0005 & 81.72 & .0003 \\
\hline$G D P h^{2}$ & -0.0068 & $<.001$ & -0.0078 & .0001 & -0.0091 & .0001 \\
\hline Time & - & - & -153 & .37 & -548 & .16 \\
\hline Time & - & - & - & - & 13.2 & .26 \\
\hline \multirow{2}{*}{ ADF on residuals } & Lags & p-value & Lags & p-value & Lags & p-value \\
\cline { 2 - 7 } & 1 & .009 & 1 & .028 & 1 & .029 \\
\hline
\end{tabular}

The Johansen tests use the Vector Error Correction Model representation of the (potentially) cointegrated sys-

\footnotetext{
${ }^{11}$ The AIC corrected for finite sample size has been used, that is $A I C=2 k-2 \ln L$ where $L$ is the likelihood, $k$ is the number of parameters.
} 
tem,

$$
\Delta y_{t}=\mu+\Pi y_{t-1}+\sum_{i=1}^{p-1} \Gamma_{i} \Delta y_{t-i}+\varepsilon_{t}
$$

where the vector $y$ contains this time all the potentially cointegrated variables in the relation of interest (that is, Deforestation, $G D P h$ and $G D P h^{2}$ ). The intercept term $\mu$ has no time index as that would imply a trend, that has just been rejected. The index $p$ is the maximum number of lags. Both Johansen tests (Lmax and Trace) are on the rank of the $\Pi$ matrix; they are carried out by testing the significance of the eigenvalues of a closely related matrix. If all these eigenvalues are significantly different from zero (p-values under 5\%), then no process is a unit root (cointegration is impossible); if none, then no linear combination of $y$ is $I(0)$, that is no cointegration. If at least one eigenvalue is non zero, then the $y$ is $I(1)$, but some linear combination is $I(0)$. The "Unrestricted constant" or "Restricted constant" cases depend on whether GDPh can be seen to have a drift or not ; this is beyond the scope of the present study. It turns out that the coefficients of the cointegration relation do not change in any significant way in either cases. The Johansen tests results are presented in Table (4).

Table 4: P-values of the Johansen trace (corrected for sample size) and L-max tests

\begin{tabular}{|c|c|c|c|c|c|c|c|c|c|c|c|}
\hline \multirow{2}{*}{$\begin{array}{c}p \\
\text { Lag- } \\
\text { order }\end{array}$} & \multirow[t]{2}{*}{ Rank } & \multicolumn{2}{|c|}{$\begin{array}{l}\text { Unrestricted } \\
\text { constant }\end{array}$} & \multicolumn{2}{|c|}{$\begin{array}{l}\text { Restricted } \\
\text { constant }\end{array}$} & \multicolumn{2}{|c|}{$\begin{array}{c}\text { No } \\
\text { constant }\end{array}$} & \multicolumn{2}{|c|}{$\begin{array}{l}\text { Restricted trend } \\
\text { unrestricted cst }\end{array}$} & \multicolumn{2}{|c|}{$\begin{array}{l}\text { Unrestricted trend } \\
\text { and constant }\end{array}$} \\
\hline & & Trace & Lmax & Trace & Lmax & Trace & Lmax & Trace & Lmax & Trace & Lmax \\
\hline \multirow{3}{*}{1} & 0 & .003 & .006 & .001 & .006 & .001 & .032 & .011 & .015 & .022 & .050 \\
\hline & 1 & .076 & .043 & .026 & .016 & .004 & .006 & .163 & .107 & .160 & .110 \\
\hline & 2 & .688 & .676 & .676 & .402 & .085 & .087 & .591 & .587 & .940 & .938 \\
\hline \multirow{3}{*}{2} & 0 & .052 & .095 & .095 & .132 & .040 & .148 & .043 & .175 & .032 & .162 \\
\hline & 1 & .163 & .115 & .115 & .135 & .072 & .100 & .089 & .096 & .071 & .045 \\
\hline & 2 & .503 & .484 & .484 & .466 & .157 & .158 & .327 & .324 & 730 & .721 \\
\hline
\end{tabular}

Above lag-order three, the results become less clear-cut, with several instances of p-values $\geq .15$ for all ranks, indicating no cointegration relation.

Deforestation, $G D P h$ and $G D P h^{2}$ thus appear cointegrated. "No trend" cases are preferred as GDPh and Deforestation data do not appear to include a (linear or quadratic) trend since a deterministic trend does not appear significant in the Engle-Granger test. Cointegration remains in tests with or without trend, restricted or not, but longer lags make it disappear. Adding the cube of GDPh (as in Day and Grafton 2003 [10]) leads to peculiar results: a cointegration relation (1) without significant regressor for the Engle-Granger test; all eigenvalues significantly different from zero for the Johansen tests, leading to rejection of the cointegration relation. A linear relation between deforestation and GDPh is not as clearly cointegrated, with or without population growth; this will be detailed in the sequel. 


\subsection{Estimated Relation}

This section presents the results of estimation for the cointegrated Deforestation- $G D P h-G D P h^{2}$ relation, that is, excluding other regressors, as argued at the beginning of the section. As shown by Engle and Granger (1987) [12], the preliminary estimation of $\beta$ in the cointegration relation does not affect the asymptotic efficiency of the estimators of the parameters in the VECM representation (3). A number of estimators could be used. Table (5) presents two estimates, a simple OLS of model (2) and one maximum likelihood of the VECM representation (3). ${ }^{12}$ Only one lag has been specified as that seemed the best choice following the tests of cointegration. ${ }^{13}$ The restricted constant version of the VECM has been selected, that is, assuming no drift in GDPh. The maximum likelihood coefficients are similar to OLS. It is also worth noting that the Lag one period of Deforestation is included in the VECM representation; when it is included in an OLS estimator of the EKC relation (2), it is largely insignificant. Although not the same as Granger causality, ${ }^{14}$ that supports the idea that the observed significance levels are not spurious.

Table 5: Regression Results

\begin{tabular}{|c|c|c|c|c|c|c|}
\hline \multirow{2}{*}{ Defor $_{t}$} & \multicolumn{5}{|c|}{ Levels } & \multicolumn{2}{c|}{ First-differences } \\
\cline { 2 - 7 } & $\hat{\beta}_{\text {OLS }}$ & $\mathrm{p}$-value & $\hat{\beta}_{V E C M}$ & $\mathrm{p}$-value & $\hat{\beta}_{\text {OLS }}$ & $\mathrm{p}$-value \\
\hline \hline Intercept & -115973 & .0011 & -130170 & .0010 & -627.2 & .30 \\
\hline$G D P h_{t}$ & 60.36 & .0001 & 64.41 & .0002 & 45.5 & .007 \\
\hline$G D P h_{t}^{2}$ & -0.0068 & .00003 & -0.0069 & .0001 & -0.0042 & .015 \\
\hline $\mathrm{T}$ & \multicolumn{2}{|c|}{39} & \multicolumn{2}{|c|}{37} & \multicolumn{2}{c|}{38} \\
\hline$R_{\text {adj } j}^{2}$ & \multicolumn{2}{|c|}{.56} & \multicolumn{2}{|c|}{-} & \multicolumn{2}{c|}{.05} \\
\hline
\end{tabular}

Graphically, the fitted deforestation is presented in Figure (2).

\footnotetext{
${ }^{12}$ Estimation used the econometric package Gretl [8]. In general, the maximum likelihood estimator for the restricted VECM problem has no closed form solution. Numerical methods are used instead, by default (in Gretl), the switching algorithm.

${ }^{13}$ Specifying lag-order two in the VECM representation since this means using $\Delta y_{t-1}$ as regressor.

${ }^{14}$ Following Wooldridge [37], we say that $z$ Granger causes $y$ if $E\left(y_{t} \mid I_{t-1}\right) \neq E\left(y_{t} \mid J_{t-1}\right)$ where $I_{t-1}$ contains past information on $y$ and $z$, and $J_{t-1}$ contains only information on past $y$.
} 
Figure 2: Fitted Deforestation with EKC

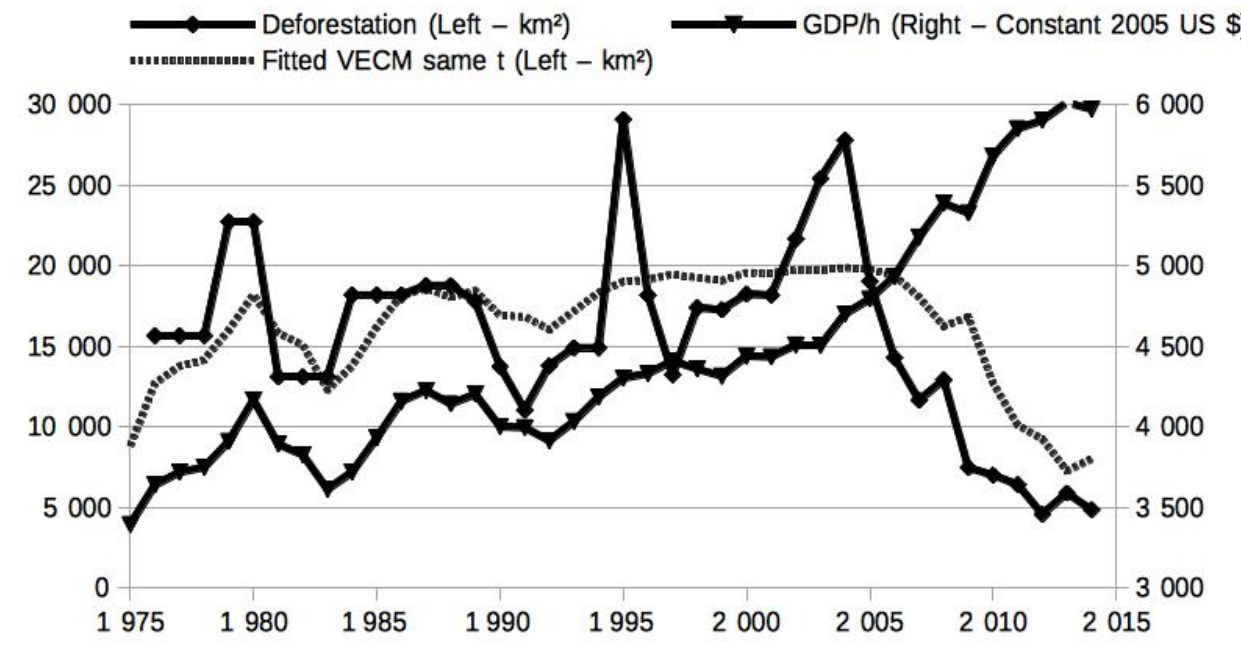

A legitimate question at this stage is whether the Legal Amazon follows a forest "transition path". That is, at what point can it be said that deforestation started declining, once removed the possible noise. It turns out that the result of the present, cointegration analysis, is remarkably similar to Kauppi et. al. 2006 [20] : about $\$ 4,600 \mathrm{GDP}$ per capita. Apart from the $R^{2}$ measure, it is interesting to note how earlier deforestation (small effect of $G D P h^{2}$ ) matches well $G D P h$, indicating the importance of as long a series as possible; and how later deforestation also matches well later $G D P h$ in negative, indicating the quadratic relation.

It is a hypothesis that the EKC relation is between variables in same period. In the case of $\mathrm{CO}_{2}$ emissions and $G D P h$, the long run relation is that it is the economic activity that is the basis for computing the GHG emissions for each country or region following the IPCC GHG 2006 protocol [11]. For deforestation, the "same period" hypothesis has no such clear-cut justification as one could argue that income anticipations, that is opportunities, are the drivers of deforestation, while it is also true that past low income in forestry, or more generally in agriculture, might drive people out of the countryside towards the city. Both likely play a role, but the small size of the sample incites to use minimal information, thus using only one time period of income, preferably the present if there is not clear improvement with another period.

Graphically, it may seem that a lead of GDPh drives deforestation a little better. Looking at the VECM representation with one lag, deforestation and lead one period of $G D P h$ and $G D P h^{2}$ are also cointegrated following 
the same test methodology as outlined above. The results of the regressions are presented in Table 6 .

Table 6: Regressions with one lead

\begin{tabular}{|c|c|c|c|c|c|c|c|c|c|}
\hline Defor $_{t}$ & $\hat{\beta}_{O L S}$ & p-value & $\hat{\beta}_{V E C M}$ & $\mathrm{p}$-value & Defor $_{t}$ & $\hat{\beta}_{O L S}$ & $\mathrm{p}$-value & $\hat{\beta}_{V E C M}$ & $\mathrm{p}$-value \\
\hline Intercept & -115973 & .0011 & -130170 & .0010 & Intercept & -143697 & .00004 & 68624 & .1137 \\
\hline$G D P h_{t}$ & 60.36 & .0001 & 64.41 & .0002 & $G D P h_{t+1}$ & 71.43 & .000003 & 41.28 & .0281 \\
\hline$G D P h_{t}^{2}$ & -0.0068 & .00003 & -0.0069 & .0001 & $G D P h_{t+1}^{2}$ & -0.0078 & .000001 & 0.0049 & .0130 \\
\hline$R_{a d j}^{2}$ & .56 & & & & $R_{a d j}^{2}$ & .59 & & & \\
\hline $\mathrm{T}$ & 39 & & $\mathrm{~T}$ & 37 & $\mathrm{~T}$ & 38 & & $\mathrm{~T}$ & 36 \\
\hline
\end{tabular}

The OLS estimators generally perform better with one lead while the VECM estimator does not fit as well, as is graphically apparent in Figure (3). Ultimately, the VECM model without lead is selected.

Figure 3: Fitted Regressions with Lead

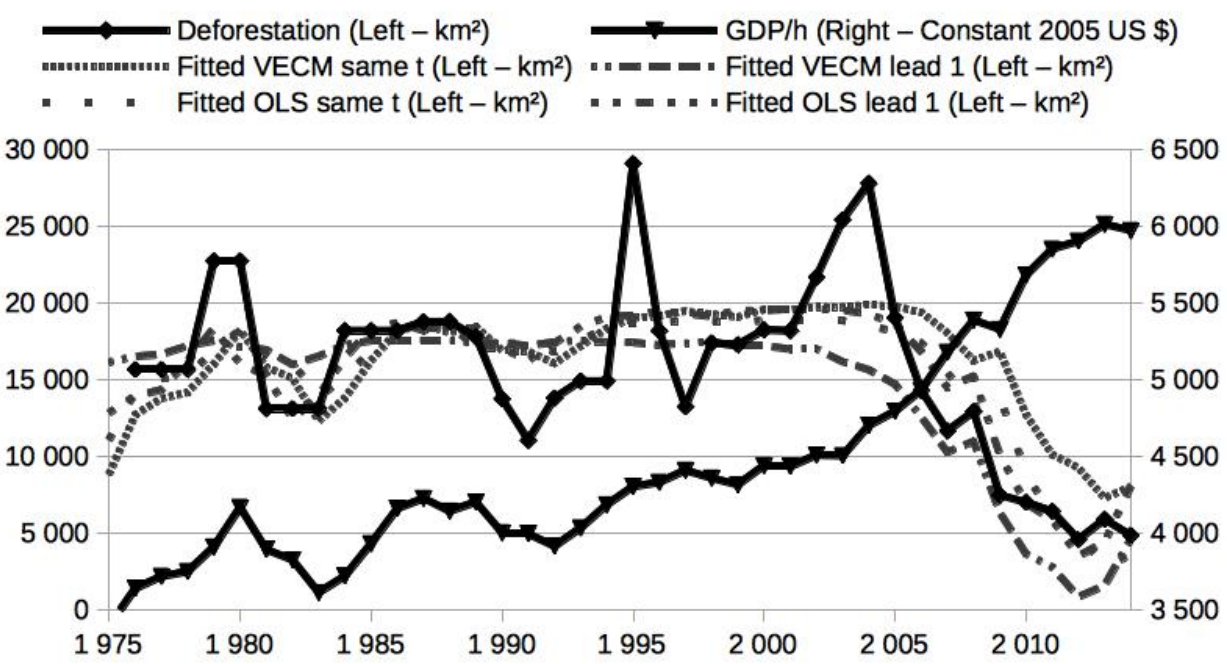

\subsection{Alternative Theories}

Stern (2004) [32] points out that even though an EKC initially seemed to exist with $\mathrm{CO}_{2}$ emissions, current literature was relatively consensual that these results were likely an artifact of the data due to the fact that 
they used cross-section or panel data. The alternative theory put forward was that pollution increases roughly monotonically with income, but "time" reduces pollution, that is, income-independent policies. In rapidly growing middle-income countries, the income effect (increasing pollution) overwhelms the time effect, but in wealthy countries, growth is slower, and pollution reduction efforts can overcome the income effect.

Stern (2004) [32] does not refer explicitly to deforestation but rather to emissions and "flow pollutants". Whether this alternative theory applies to deforestation may be tested with the current dataset since it is a time-series, and therefore immune to the previously mentioned artifact. Stern (2004) [32] has not formalized the theory, but merely indicated 3 variables : GDPh, time, Growth. It is assumed that Growth is defined as Growth $_{t}=\left(G D P h_{t}-G D P h_{t-1}\right) / G D P h_{t-1}$.

Several formalizations may be suggested but cointegration issues must first be examined. Time is not stochastic, so it is exogenous and not "cointegrated". Growth is $\mathrm{I}(0)$ following the ADF and PP tests. Thus the cointegration is really between deforestation and $G D P h$. The cointegration tests applicability is a delicate issue because of the possible trend $t$. The tests are between Deforestation and GDPh, but there is no apparent (graphical) trend. The Engle-Granger test produces a p-value of 5.3\% without trend and 3.5\% with trend. The Johansen tests use growth as an "exogenous" regressor and produce all p-values under 5\% threshold (no cointegration) without trend. But with trend, the p-values change from under to above 5\% (this disappears with 2 lags). Thus, cointegration is possible between Deforestation and GDPh, but it is not as clear-cut as with the EKC. Several estimators are consistent under cointegration of Deforestation and GDPh: OLS and maximum likelyhood of the VECM representation have been used as before.

Formalization 1 : Linear Growth

$$
\text { Defor }_{t}=\beta_{0}+\beta_{1} \text { GDPh }_{t}+\beta_{2} \text { Growt }_{t}+\beta_{3} t+\varepsilon_{t}
$$

This formalization is a direct interpretation of Stern's (2004) [32] theory. The trend $t$ may be included directly as a regressor since it is deterministic. Growth is $\mathrm{I}(0)$ and can thus also be used directly as a regressor. The expected signs are $\beta_{1}>0, \beta_{2}>0$ and $\beta_{3}<0$ so that Growth increases deforestation, as well as income, while time decreases it; but the OLS and VECM estimates are such that $\hat{\beta}_{1}<0, \hat{\beta}_{2}<0$ and $\hat{\beta}_{3}<0$, all significant at conventional levels. An ADF test rejects a unit root in the residuals, whether a trend is included in the test or not. That is, it can reasonably be stated that, in the case of the Brazilian deforestation series, time and growth 
tend to increase deforestation while income would decrease it. Thus, the actual results are opposite the theory for 2 out of the 3 coefficients.

Formalization 2 : Quadratic Growth

$$
\text { Defor }_{t}=\beta_{0}+\beta_{1} G D P h_{t}+\beta_{2} \text { Growth }_{t}+\beta_{3} \text { Growth }_{t}^{2}+\varepsilon_{t}
$$

This formalization has no explicit role for time as slow growth accounts for the "time" effect. It is expected that $\beta_{1}>0, \beta_{2}<0$ and $\beta_{3}>0$. Growth can be included in levels as it is $\mathrm{I}(0)$. The OLS and VECM estimates are $\hat{\beta}_{1}<0, \hat{\beta}_{2}>0$ and $\hat{\beta}_{3}<0$, all significant at conventional levels. The ADF test on the residuals of this regression indicates ambiguous results, depending on whether a trend is included in the test or not. Thus a unit root cannot be rejected unambiguously at conventional levels. Assuming that no unit root exist in the residuals, the regression results indicate that income tends to decrease deforestation, while growth appears in a quadratic relation with signs opposed to the expected ones.

Formalization 3: time. Barring the possible effect of growth, Stern's (2004) [32] theory might be interpreted as a statement that "time alone" is responsible for the observed decrease in deforestation. Time is a pure (nonstochastic) trend, it cannot be cointegrated, but the logic of the Engle-Granger test can still be applied on time by regressing deforestation against time and squared-time and testing whether the residual series is $I(0)$. In that case, the deforestation series would simply be following a quadratic trend, but that is not the case. Table (7) shows the OLS estimates of such a formalization and the result of the ADF test indicating that the residuals of that regression still contain a unit root. As shown in Table (3), when including GDPh and its square in this formalization, the significance of time disappears entirely.

Table 7: ADF test on the residuals of Defor $_{t}=\beta_{0}+\beta_{1} t+\beta_{2} t^{2}+\varepsilon_{t}$

\begin{tabular}{|c|c|c|}
\hline Regression & Coef. estimate & $\mathrm{p}$-value \\
\hline \hline Intercept & 12390 & 0 \\
\hline$t$ & 793 & .01 \\
\hline$t^{2}$ & -23.6 & .001 \\
\hline \multirow{2}{*}{ ADF on residuals } & Lags & p-value \\
\cline { 2 - 3 } & 1 & .14 \\
\hline
\end{tabular}


As a conclusion, it seems reasonable to assert that the EKC theory is more coherent with the Legal Amazon deforestation time-series than any of the three alternative theories considered.

\section{Unobserved Heterogeneity}

Stern (2004) [32] identifies four issues in the literature. The first is heteroskedasticity, but Stern was referring to panel or cross-section studies. It is difficult to argue that heteroskedasticity can be an issue in the present deforestation time-series. Classical tests do not reject homoskedasticity. The second is simultaneity. In the present case, this amounts to asking whether deforestation causes GDP. The whole of the Brazilian agriculture is about 5 to $6 \%$ of GDP (World Bank data) at the end of the series, about $12 \%$ at the beginning. Therefore, even if there was simultaneity, its relative size appears small. The third is omitted variables, that is, more generally, unobserved heterogeneity, which is the subject of the present section. The fourth issue identified in the literature is cointegration, which has been discussed in the previous section, but which also pervades the present section.

Unobserved heterogeneity may take several forms, but in the present case, the main concern will be omitted regressors. It is worth to mention also parameter stability, that is, in the present case, model (2) would become

Defor $_{t}=\beta_{0 t}+\beta_{1 t} G D P h_{t}+\beta_{2 t} G D P h_{t}^{2}+\varepsilon_{t}$. The coefficient may now change every period. Generally, such a model is not identified without further restriction, but if it is indeed the case that $G D P h$ has a changing effect on deforestation, then it is a well-known cause of endogeneity since then the varying part of the coefficients find themselves in the error term. One reason the coefficients of model (2) could be changing with time is that deforestation has seen different regimes since the beginning of the series, as mentioned in the introduction. First, in the 70-80s, deforestation was encouraged by means of subsidies, then in the 90s and early 2000s, it may have been primarily correlated to meat prices, and then, starting in 2004, the Action Plan was implemented. These regimes will be examined later on using a regressor approach, but at present, it is difficult to rule out the possibility of changing parameters in the present context because the length of the series does allow for reasonably-sized tests.

Omitted regressor(s) might cause endogeneity when the omitted regressor is correlated with the included regressors. A cointegrated relation is comforting since then residuals are stationary and I(0) - i.e. close to a white noise - and a white noise is generally uncorrelated with other series; therefore endogeneity-causing unobserved heterogeneity might be unlikely in the present case. It is also worth to note the "super consistency" of Least 
Squares in the error correction model of Stock and Watson 1993 [34], Stock [33] and Phillips [28], where lags of the dependent variable account for the unobserved heterogeneity. That is, the VECM estimator that has been used may still be consistent even with unobserved heterogeneity. Nevertheless, the remainder of this section will explore additional regressors to the EKC relation, not only in an attempt to eliminate any source of endogeneity, but also to improve understanding of the relation, particularly regarding the current Action Plan policy.

\subsection{Additional Explanatory variables}

In testing an EKC, that is, linking Deforestation and a quadratic function of Income, adding regressors might reduce unobserved heterogeneity. Also, income appears causal in a cointegration sense, but it could capture the effect of other variables, such as agriculture prices, population or public policy. In the sequel, these additional regressors are introduced and it is examined whether they alter the cointegration tests results. It is also tested whether these regressors are cointegrated with deforestation without GDPh in the relation. As indicated earlier, in Brazil, little deforested land is turned in urbanized area, and not much wood is used or exported, so that urbanization or forestry are unlikely drivers; most of the deforested is turned in pasture and some in soy fields. ${ }^{15}$

Soybean and meat prices might then be expected to play a role in deforestation. This issue has been recently investigated in Assunção et.al. (2012) [3], but not in a time-series context, and therefore not in a cointegration / EKC context. The price data are the World Bank Pink Sheet; they are world prices averages and therefore can safely be considered exogenous to the Deforestation equation (2). The two price series are quite correlated $(65 \%)$ to each other ${ }^{16}$ and are both clearly $I(1)$; the usual test show that neither is in a cointegration relation that includes Deforestation and Income. Therefore, inclusion of either price series in the Deforestation model (2) induces a risk of spurious result. Regressing the first difference of Deforestation on the first difference of Meat price fails to produce any significant result. These results may appear in contrast with the belief that cattle ranching is a causal factor, e.g. World Bank [22] or Nasa Earth Observatory (footnote 4). They suggest that cattle ranching developed in the Amazon because of lack of better opportunities elsewhere. These opportunities may currently be present or alternatively, the cost of deforestation has risen.

Figure (4) shows that both agricultural prices roughly fall until the end of the 1990's before starting to recover. This pattern is not easily reconcilable with the deforestation series that increased relatively slowly (with peaks) until the mid-2000', then started to decrease.

\footnotetext{
${ }^{15}$ Whether agriculture proceeds more from small scale farming or larger scale commercial farming is beyond the scope of this work.

${ }^{16}$ They are in fact cointegrated.
} 
Figure 4: Agricultural Prices Series, ANnUAl Prices, ReAl 2010 US\$

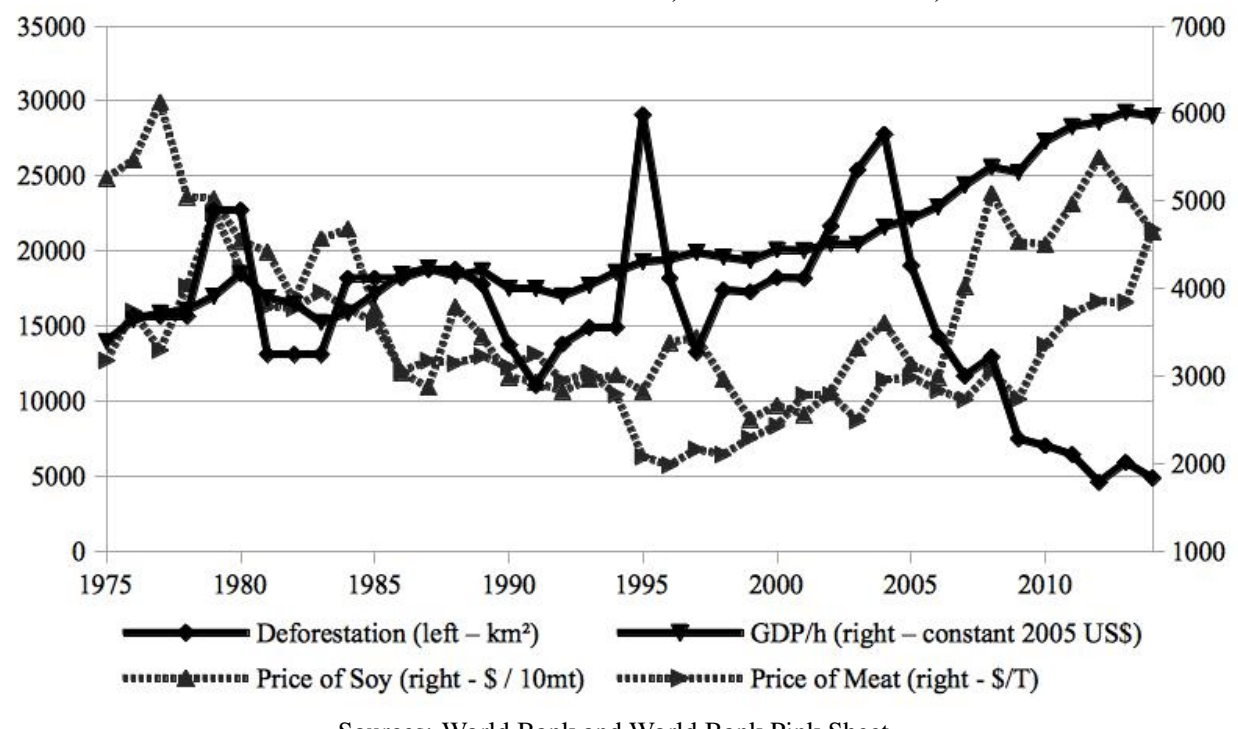

Sources: World Bank and World Bank Pink Sheet

Population. It is customary (see e.g. Bernard et.al. 2011 [5] on the time series properties of emissions curves), to model per capita emissions as a function of per capita GDP and other variables. Such an approach restricts the role of population on total emissions since it implies that individuals emit the same amount in every year, so that the series in level and per capita behave similarly. It is certainly the case that emissions proceeds ultimately from individuals, so that it is natural to express emissions per habitant. However, that is clearly not the case with deforestation. That is why, contrarily to custom in the EKC literature, the present paper has considered the yearly total deforested area.

Thus, even though Brazilian population pressure is not usually considered an important driver of deforestation, it is of interest to examine its possible relation with deforestation. The tests presented in Table 2 show that the population series presents a unit root both in levels and in first-differences. The same results hold when testing with constant or with constant and trend, so that it is possibly trending. Therefore, if population is to play a role in explaining deforestation, it has to be cointegrated. The Engle-Granger cointegration test on the Population series yield the results presented in Table (8), lead to the conclusion that Deforestation, Population and its square are not cointegrated. 
Table 8: Engle-Granger Cointegration Test on the Population series

\begin{tabular}{|c|c|c|}
\hline Coint. regression & Coef. estimate & p-value \\
\hline \hline Intercept & -61178 & .04 \\
\hline pop & 1.08 & .007 \\
\hline pop $^{2}$ & $-3.7 \mathrm{E}-06$ & .004 \\
\hline \multirow{2}{*}{ ADF on residuals } & Lags & p-value \\
\cline { 2 - 3 } & 1 & .23 \\
\hline
\end{tabular}

Adding population to the EKC relation does not change the results regarding $G D P h$, but makes Population non significant. Similar results hold when using population first differences ("pressure") instead of levels. Therefore, there is no apparent effect of population pressure. This is consistent with the fact that relatively little of the deforested area goes to urbanization (Nasa Earth Observatory, see footnote 4). Also, total population increases smoothly, while the rural population decreases smoothly: this is not consistent with the deforestation series which shows an abrupt change about 2005.

\subsection{Untested Drivers}

Even though other determinants might be important, such as the socio-economic factors as in Araujo et al. [2], they do not seem available for comparably long time-series. Their potential importance is reviewed in the present subsection. Although there is a non-spurious relation between Income and Deforestation in the Legal Amazon, it should be clear that cointegration merely indicates that as Income increases, Deforestation becomes less appealing. A number of more structural reasons, or alternatives, have been evoked in the literature, e.g. Day and Grafton (2003) [10] and Stern (2004) [32] for the economic ones, and Rudel et.al (2005) [29] and Geist and Lambin (2001) [16] for the geographic ones. They can be summarized as follows.

Forestry jobs (and more generally agricultural jobs) becoming relatively less attractive than others as suggested in Rudel et.al. [29], Kauppi et.al. (2006) [20] and Lambin and Meyfroidt (2011) [21]. If that is true, a shift in job pattern should be apparent, so that agricultural employment (or its share in total employment) might show a pattern similar to deforestation. Graphically, that seems to be the case for the labor force in agriculture as percentage of the total. Even though the rural population declines smoothly, the labor force in agriculture appears to fall more sharply. Using the total number of people working in agriculture, the relationship with 
$G D P h$ is not linear, but matches well deforestation as it roughly grows until 2003, then starts declining. This is illustrated in Figure (5), but the number of missing data precludes a meaningful regression. A forestry wages series should also reflect the shift, but there does not seem to exist reliable rural wages series.

More speculatively, higher incomes also induce higher government resources. Concurrently, higher spending in education per head is made possible, and thus more opportunities for children. Poverty reduction programs are also made possible. For these two series, as illustrated in Figure (5), the data appear wildly varying, or missing, until the mid-90's, where they remain roughly stable until about the mid-00's; after that, both poverty reduction and expenditure in education clearly accelerate. The number of missing data also precludes a formal time-series regression.

Figure 5: Employment, Poverty, EducAtion

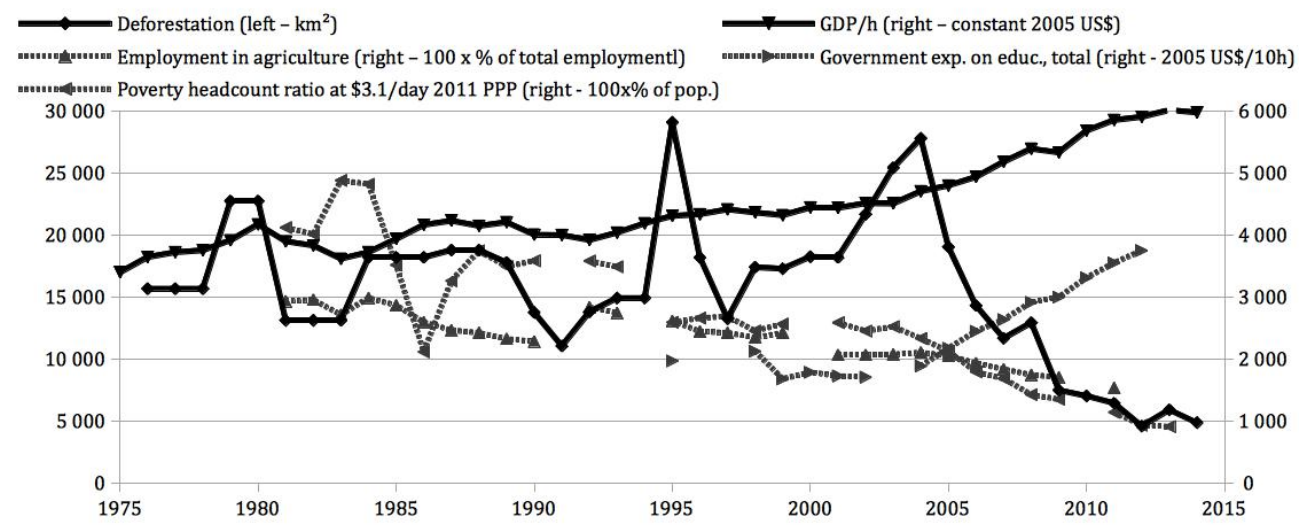

Technological progress that reduces needs for forest products (substitution of materials, more efficient transformation technology). This is difficult to test in the present forestry context as technology might be imported, and thus unrelated to Brazilian income. Assuming that technological progress is adequately modeled by a time trend, this potential cause has been ruled out under "alternative theory 3" earlier.

Rudel et al. (2005) [29] suggest scarcity of forest itself, such as which prompted Asian nations to implement re-forestation programs (e.g. Bangladesh, India and China). Forest scarcity seems an unlikely hypothesis since the Amazonian forest cover is $87 \%$ (about $640000 \mathrm{~km}^{2}$ deforested out of 4.9 million $\mathrm{km}^{2}$ of the Legal Amazon), compared to e.g. $7 \%$ in China. But ultimately, this is a matter of perception by the authorities in charge of the forestry policy, for which there is no data. 
Finally, awareness of and ability to measure and resolve environmental problems. This is testable as the effect of the Action Plan policy and will be addressed in the next section. The ability to measure is roughly constant since 1975, first year of LandSat data, but although awareness of amazonian deforestation is acute since then (as testified in the early publications such as Fearnside 1982 [14] and Skole and Tucker [31]), the ability to address the problem appears to be relatively recent since the Action Plan policy has only been decided in 2004.

Consequently, it appears that the fall of deforestation since the mid-00s in the Legal Amazon is consistent with a number of geographical sciences publications that interpret that economic development makes deforestation become relatively less attractive than other activities.

\subsection{Action Plan}

The Action Plan for Prevention and Control of the Legal Amazon Deforestation (Plano para Prevenção e Controle do Desmatamento na Amazônia - PPCDAm) is a policy that started in 2004. ${ }^{17}$ Its budget is set per "phase", the current third phase ended in 2015. Phase $1: 2004-08$ had a budget of 394 MB\$ nominal; Phase 2 : 2009-11: 952 MB\$ nominal; Phase 3 : 2012-15: 870 MB\$ nominal.

On occasion, policies maybe be represented by a dichotomous variable indicating the start of the policy when they are exogenous to the relation being studied. Representing the Action Plan by such a dummy in the EKC relation leads to a non-significant coefficient estimate. However, the Action Plan Budget (APB) is I(1) both in nominal and in real terms. It is cointegrated with Deforestation when considered separately from GDPh, but is not significant in OLS or VECM estimates when added to the EKC model.

However, APB is clearly not an exogenous regressor since the policy is a sophisticated set of measures that are implemented in reaction to deforestation - a form of simultaneity. This form of endogeneity may be addressed by an Instrumental Variable estimator. Consider an extended EKC model

$$
D e f o r_{t}=\alpha+\beta_{1} G D P h_{t}+\beta_{2} G D P h_{t}^{2}+\gamma A P B_{t}+\varepsilon_{t}
$$

The selected instrument for $A P B_{t}$, is $A P B_{t-1}$. Following the Weak instrument test of Stock and Yogo, 2005 [35], the First-stage F-statistic $(1,35)=14.7487$ while a value $<10$ may indicate weak instruments. Thus

\footnotetext{
${ }^{17}$ Brazilian Ministry for the Environment - Ministério do Meio Ambiente http://www.mma.gov.br/florestas/controle-epreven\%C3\%A7\%C3\%A3o-do-desmatamento/plano-de-a\%C3\%A7\%C3\%A3o-para-amaz\%C3\%B4nia-ppcdam
} 
$A P B_{t-1}$ is a somewhat weak instrument, but still has some validity. In a non-cointegrated time-series context, it would be difficult to use such instrument because it is likely that the error term of the model would be strongly persistent (i.e. a shock at some point has everlasting effect) and since the $A P B$ regressor is also $I(1)$, it is strongly correlated with its own past. Consequently, past values of $A P B$ may be correlated with present value of the error term because of the strong persistence, causing inconsistency of the IV estimator. However, because of the co-integrated relation Deforestation-GDPh-GDPh$h^{2}$, the residuals of the IV estimator of the $A P B$ model (4) are $I(0)$, that is, not strongly persistent, making more legitimate the use of the lag of $A P B$ as an instrument for $A P B$, and making legitimate the inference from the IV estimator. The results of the IV regression are presented in Table (9).

Table 9: IV Regression Results

\begin{tabular}{|c|c|c|}
\hline Defor $_{t}$ & $\hat{\beta}_{I V}$ & $\mathrm{p}$-value \\
\hline \hline Intercept & -123436 & $\sim .002$ \\
\hline$G D P h_{t}$ & 60.31 & $\sim .0002$ \\
\hline$G D P h_{t}^{2}$ & -0.0063 & $\sim .00002$ \\
\hline$A P B_{t}$ & -19.26 & variable \\
\hline $\mathrm{T}$ & \multicolumn{2}{|c|}{39} \\
\hline
\end{tabular}

The significance of $A P B_{t}$ is questionable: the p-value varies between .03 and about .20 , depending on the chosen lag of the HAC (Heteroskedastic-Autocorrelation) robust estimates of the standard errors. Therefore, there is limited evidence for the effect of the Action Plan. With some likelihood, the effect is all EKC, but graphically, the effect of APB is more convincing, as illustrated in Figure (6).

A legitimate question is where deforestation would stand with the current $G D P h$ path, but without the Action Plan. Figure (6) shows the same Fitted VECM as in Table (5), that is, without an $A P B$ term; the IV fitted Deforestation including a term for $A P B$ as in Equation (4) and the same fitted deforestation setting the $A P B$ budget to zero. Accordingly with this simulation, the effect of the Action Plan has been quite important in the early years (2004 to approximately 2008), where it is the main cause of the observed sharp drop in 2005, but from 2009 onwards, the EKC effect appears relatively more important. 
Figure 6: Fitted Deforestation and Action Plan

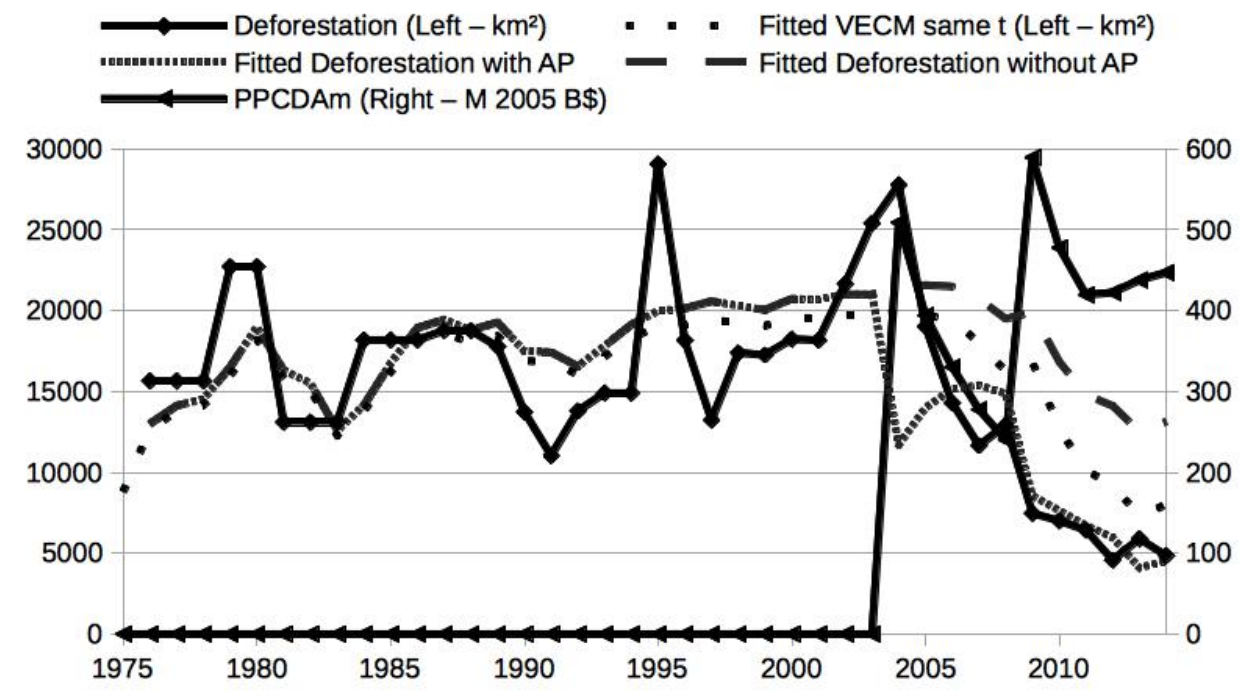

\section{Conclusions}

Using publicly available time-series data on Legal Amazon deforestation, it has been shown that income and deforestation are cointegrated following an Environmental Kuznets Curve relation. The quadratic effect in income per inhabitant is significant and robust to various specifications of the series. Alternative theories following Stern (2004) [32] have been clearly rejected. In particular, periods of fast growth cannot be associated with higher deforestation. The point when deforestation starts to decrease, corresponds to an income around 4600 in US\$2005, coincidental with results in the geography literature such as Rudel et.al. [29], Kauppi et.al. (2006) [20] and Lambin and Meyfroidt (2011) [21]. It striking that using different methods, the present paper ends up with fairly similar results.

As regressions based on cross-sections may lead to spurious EKC results as summarized in Stern (2004) [32], it is important to underline cointegration as a way to address a number of endogeneity issues surrounding the testing of an EKC using time-series. Cointegration is only a necessary condition as other issues might arise, especially the econometric specification issue of whether different countries could follow the same EKC; indeed, in panel studies, it may be argued that not only the origin, but also the slope is different among countries. Even 
though only the very special Legal Amazon has been considered, it remains that deforestation series in many countries are likely I(1) because of their long memory and therefore their levels can only be meaningfully associated with measures of income if they are cointegrated.

Amazonian deforestation appears unrelated to total population, at the national level at least, both in the short and in the long runs, and to meat or soy prices. Thus, one of the results of this paper is to show that amazonian deforestation, though an agricultural matter, is not driven by prices but by income, and that better economic opportunities tend to decrease deforestation. Therefore, the political importance of an EKC in deforestation may classicaly appear large as it may be used to favor economic growth policies over environmental-friendly policies as growth would eventually induce lower levels of deforestation. It might then be considered a waste to resist deforestation and instead, let forestry foster a quicker growth. In a context of global warming and given the importance of functioning carbon sinks, different forest policies in countries with large forest covers may make a large difference.

However, the argument may be reversed: in the long run, the EKC implies that society will collectively choose high levels of forest-cover; in the meantime, there may be lower levels. For a number reasons, an old-growth forest is preferable to a new one; this is certainly true from an ecological standpoint, with a richer genetic diversity, but also in terms of preserved surface- and ground-waters and avoided $\mathrm{CO}_{2}$ emissions. Thus, one might want to avoid the low forest levels, especially as they may not contribute significatively to growth and taking into account the current side-effects of deforestation, such a droughts.

Further, there is no evidence that the EKC relation will "naturally" continue. Obviously, it could not be the case in the long run, since forest cover cannot be higher than 100\%. Quoting Meyfroidt et. al. 2011 [23] "The onset of a possible forest recovery in a country is not automatic and can nowhere be taken for granted." The EKC relation that has been uncovered in this paper may indicate that better economic opportunities are likely to have a positive side-effect on deforestation. This points not to a growth-oriented policy, but rather to policies that would diverts targeted populations away from the forestry sector.

The Action Plan anti-deforestation policy has been investigated using an Instrumental Variable based on that policy budget. The Action Plan shows a positive effect towards reducing deforestation; it is not very strongly statistically significant, but that might be due to the relatively small size of the deforestation series. Such a result could not have been reached if the EKC cointegrated relation had not been previously identified.

Finally, it could be asked what is the future path of deforestation of the Legal Amazon, and especially when it 
would reach zero. That depends on the evolution of GDPh and on the budget of the Action Plan. Assuming the later remains at its 2014 level, and using GDPh forecast from the IMF[19] up to 2020, taking linear interpolation for the missing years, Deforestation will go back up to about 2009 levels until about 2018 when growth returns. The turning point, when deforestation is zero, might be reached a little after 2020, when GDPh is about 62006300 in US\$2005, ${ }^{18}$ as illustrated in Figure 7.

FIGURE 7: FORECAST DEFORESTATION

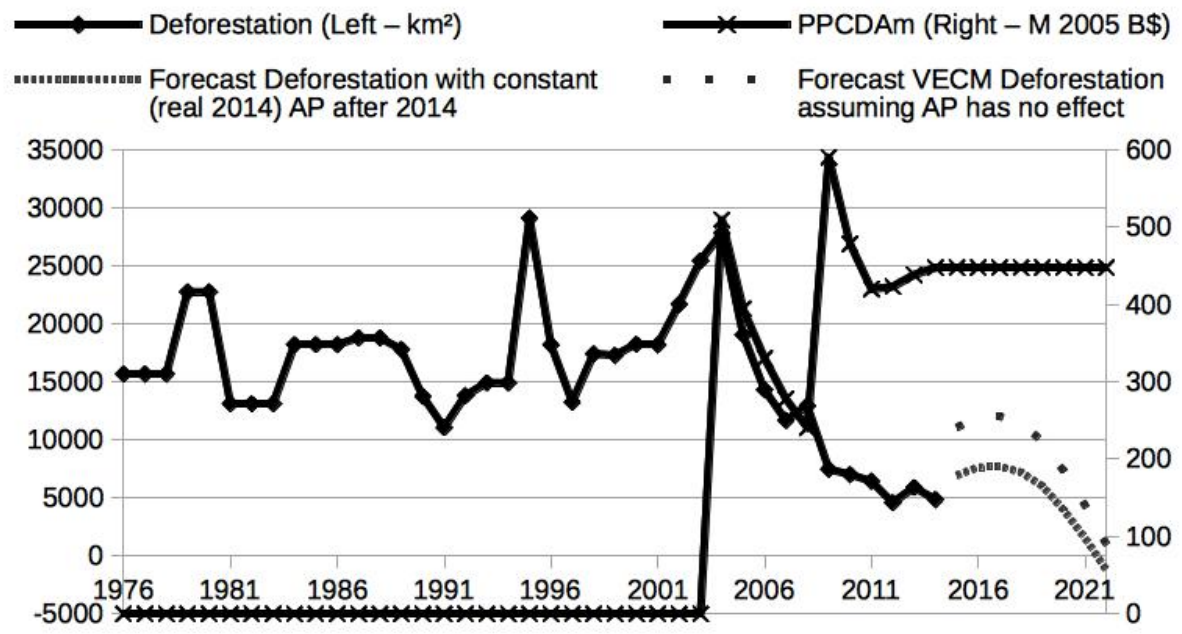

\section{References}

[1] L. E. Andersen, C. W. Granger, E. J. Reis, D. Weinhold, and S. Wunder. The dynamics of deforestation and economic development in the Brazilian Amazon. Cambridge University Press Cambridge, 2002.

[2] C. Araujo, C. A. Bonjean, J.-L. Combes, P. Combes Motel, and E. J. Reis. Property rights and deforestation in the Brazilian Amazon. Ecological Economics, 68(8):2461-2468, 2009.

[3] J. Assunção, C. C. e Gandour, and R. Rocha. Deforestation slowdown in the Legal Amazon: Prices or policies? Climate Policy Initiative / PUC-Rio working paper, 2012.

\footnotetext{
${ }^{18}$ It is possible to compute a confidence interval for such measure following [5], but in the present context confidence interval may convey a false sense of the possible, since actual deforestation will depend very much on policy variables.
} 
[4] E. B. Barbier and J. C. Burgess. The economics of tropical deforestation. Journal of Economic Surveys, 15(3):413-433, 2001.

[5] J.-T. Bernard, M. Gavin, L. Khalaf, and M. Voia. The Environmental Kuznets Curve: tipping points, uncertainty and weak identification. Cahier de recherche/Working Paper, page 4, 2011.

[6] M. Bhattarai and M. Hammig. Institutions and the environmental Kuznets curve for deforestation: a crosscountry analysis for latin america, africa and asia. World development, 29(6):995-1010, 2001.

[7] J. Choumert, P. Combes Motel, and H. K. Dakpo. Is the environmental Kuznets curve for deforestation a threatened theory? a meta-analysis of the literature. Ecological Economics, 90:19-28, 2013.

[8] A. Cottrell and R. Lucchetti. Gretl user's guide. Included in Gretl Econometrics Package, October 2014.

[9] R. Culas and D. Dutta. A re-examination of causes of deforestation and environmental Kuznets curve: evidences from Latin America, Africa and Asia. Department of Economics, 2003.

[10] K. M. Day and R. Q. Grafton. Growth and the environment in Canada: An empirical analysis. Canadian Journal of Agricultural Economics/Revue canadienne d'agroeconomie, 51(2):197-216, 2003.

[11] H. Eggleston, L. Buendia, K. Miwa, T. Ngara, and K. Tanabe, editors. 2006 IPCC Guidelines for National Greenhouse Gas Inventories. IGES, Japan, 2006.

[12] R. F. Engle and C. W. Granger. Co-integration and error correction: representation, estimation, and testing. Econometrica: journal of the Econometric Society, pages 251-276, 1987.

[13] R. M. Ewers, W. F. Laurance, and C. M. Souza. Temporal fluctuations in amazonian deforestation rates. Environmental Conservation, 35(04):303-310, 2008.

[14] M. Fearnside. Desmatamento na Amazônia brasileira: com que intensidade vem ocorrendo (?). Acta Amaz, 12, 1982.

[15] Forestry Canada. The state of forestry in Canada 1990 report to parliament. Technical report, Minister of Supply and Services, 1991.

[16] H. J. Geist and E. F. Lambin. What drives tropical deforestation. LUCC Report series, 4:116, 2001.

[17] G. M. Grossman and A. B. Krueger. Environmental impacts of a North American free trade agreement. National Bureau of Economic Research NBER Series, 3914, 1991. 
[18] G. M. Grossman and A. B. Krueger. Economic growth and the environment. The quarterly journal of economics, 110(2):353-377, 1995.

[19] IMF. Adjusting to lower commodity prices. In World Economic Outlook. International Monetary Fund, October 2015.

[20] P. E. Kauppi, J. H. Ausubel, J. Fang, A. S. Mather, R. A. Sedjo, and P. E. Waggoner. Returning forests analyzed with the forest identity. Proceedings of the National Academy of Sciences, 103(46):17574-17579, 2006.

[21] E. F. Lambin and P. Meyfroidt. Global land use change, economic globalization, and the looming land scarcity. Proceedings of the National Academy of Sciences, 108(9):3465-3472, 2011.

[22] S. Margulis. Causes of deforestation of the Brazilian Amazon, volume 22. World Bank Publications, 2004.

[23] P. Meyfroidt, M. van Noordwijk, P. A. Minang, S. Dewi, and E. Lambin. Drivers and consequences of tropical forest transitions: options to bypass land degradation? Policy Brief, 25, 2011.

[24] R. C. d. Oliveira, E. Almeida, R. d. S. Freguglia, and R. C. S. Barreto. Desmatamento e crescimento econômico no brasil: uma análise da curva de Kuznets ambiental para a Amazônia Legal. Revista de economia e sociologia rural, 49(3):709-739, 2011.

[25] J. E. Payne, B. T. Ewing, and H. Mohammadi. The Elgar Companion to Public Economics: Empirical Public Economics, chapter Wagner's Law of Increasing Expansion of Public Activities. Edward Elgar, 2006.

[26] R. Pereira da Cunha. Avaliação da floresta amazônica. Technical report, Instituto de Pesquisas espaciais, diretora de sensoramiento remoto, 1989.

[27] R. Perman and D. I. Stern. Evidence from panel unit root and cointegration tests that the environmental Kuznets curve does not exist. Australian Journal of Agricultural and Resource Economics, 47(3):325-347, 2003.

[28] P. C. Phillips. Optimal inference in cointegrated systems. Econometrica: Journal of the Econometric Society, pages 283-306, 1991.

[29] T. K. Rudel, O. T. Coomes, E. Moran, F. Achard, A. Angelsen, J. Xu, and E. Lambin. Forest transitions: towards a global understanding of land use change. Global Environmental Change, 15(1):23 - 31, 2005. 
[30] N. Shafik and S. Bandyopadhyay. Economic growth and environmental quality: time series and cross country evidence, 1992.

[31] D. Skole and C. Tucker. Tropical deforestation and habitat fragmentation in the Amazon. satellite data from 1978 to 1988. Science(Washington), 260(5116):1905-1910, 1993.

[32] D. I. Stern. The rise and fall of the environmental Kuznets curve. World development, 32(8):1419-1439, 2004.

[33] J. H. Stock. Asymptotic properties of least squares estimators of cointegrating vectors. Econometrica: Journal of the Econometric Society, pages 1035-1056, 1987.

[34] J. H. Stock and M. W. Watson. A simple estimator of cointegrating vectors in higher order integrated systems. Econometrica: Journal of the Econometric Society, pages 783-820, 1993.

[35] J. H. Stock and M. Yogo. Testing for weak instruments in linear IV regression. Identification and inference for econometric models: Essays in honor of Thomas Rothenberg, 2005.

[36] D. Weinhold and E. Reis. Transportation costs and the spatial distribution of land use in the Brazilian Amazon. Global Environmental Change, 18(1):54 - 68, 2008.

[37] J. M. Wooldridge. Introductory Econometrics. Cengage Learning, 2012. 